\title{
About Scaling of Controlling Information System of Industrial Complex by Streamlining of Big Data Arrays in Compliance with Hierarchy of the Present Lifeworlds
}

\author{
D. Reut \\ Economics and Production Organization Department \\ Bauman Moscow State Technical University (BMSTU) \\ Strategic Planning and Management Methodology Department \\ National Research Nuclear University (NRNU) MEPHI \\ Moscow, Russia \\ Corresponding author: reut@bmstu.ru \\ S. Falko \\ Economics and Production Organization Department \\ Bauman Moscow State Technical University (BMSTU) \\ Moscow, Russia \\ E-mail: falko@controlling.ru \\ E. Postnikova \\ Economics and Production Organization Department \\ Bauman Moscow State Technical University (BMSTU) \\ Moscow, Russia \\ E-mail: postnikova.el@yandex.ru
}

(Received December 18, 2018; Accepted July 11, 2019)

\begin{abstract}
This article discusses the problem of scaling the control information system. Some new type of horizontal scaling of big data array is offered. It consists in structuring of this array in compliance with hierarchy of lifeworlds (Lebenswelt), which become distinguishable in the paradigm of large-scale system. Processes of the "lower" lifeworlds can be so slow that won't be caught by strategic analysis and design instruments of "top" lifeworlds. However, these processes can give some delayed cumulative effect called "black swan effect". The complex formation algorithms recreating the logic of the interconnection of industrial enterprise subsystems are presented. The bases of the choice of temporary horizon extension for large-scale system strategic planning are given.
\end{abstract}

Keywords- Control, Decision-making, Digital economy, Technocenosis, Hierarchy, Lebenswelt.

\section{Introduction}

Moore's law (Denning and Lewis, 2017), initially predicting only an exponential increase in the number of transistors placed by manufacturers on a single chip, but distributed today in wireless technologies (Wi-Fi, WiMAX, Bluetooth), sensor networks (Akyildiz et al., 2002; Levis et al., 2005), photonics (Knight, 2017; Metz, 2018), etc., presages a decisive introduction of the big data technologies into the organization of industrial enterprises (Tishina et al., 2017; Gorodetskiy et al., 2018).

Introduction of big data technology seems the most dynamic direction of the evolution of an enterprise, considered as an instance of the technocenotic essence (Cukier, 2013; Mayer- 
International Journal of Mathematical, Engineering and Management Sciences

Vol. 4, No. 5, 1127-1139, 2019

https://dx.doi.org/10.33889/IJMEMS.2019.4.5-089

Schönberger and Cukier, 2013; Grishchenko et al., 2016).

Within the framework of an industrial enterprise, the main consumer of information contained in large data arrays is the controlling subsystems (Romanenko et al., 2016).

Controlling is a service subsystem of a management system (of an industrial enterprise, a production complex, an industry branch) that provides the collection of the volume of information necessary for the management needs, correct usage of methods and tools for planning, monitoring, analysis, decision making, transparency and visibility presentation of the results achieved. Controlling is an intermediate link between managerial and objective activity, the focus of high management technologies (Reut, 2013). Sometimes some special mathematical instruments are used in this area (Kozlov et al., 2016). Therefore, we are talking about controlling in connection with the big data technologies. The need to introduce, maintain and improve the controlling subsystem as a structural and functional subdivision of the management system is explained by anthropological reasons. Information "capacity" of any manager, i.e. its ability to perceive and process information, to make adequate decisions and track feedback in the face of time constraints is limited and practically close to exhaustion in fastest-progressing industrial enterprises. In the critical areas of the management structure the need for the servicing function of controlling is particularly acute. In modern practice it is usually situationally satisfied with the creation of a controlling service. As the organization of such services takes a spontaneous and mass character, it is time to comprehend this process as an institutionalization of the controlling idea. The creation of the institute of controlling is the natural spread of the trend of universal specialization to managerial activity - the process which gave rise to the European bourgeois industrial revolution of the 18th century and all subsequent European progress. The creation of the controlling institute allows production relations to reach a fundamentally new level, corresponding to the current level of development of the productive forces. Controlling provides an obvious increase in the effectiveness of decision-making. It increases the competitiveness of enterprises that have introduced it. However, in large-scale systems of any country, controlling is used poorly today because such systems are monopolies of their markets and do not feel the need to increase efficiency. The trend of universal globalization will sooner or later force these monopolists to introduce controlling subsystems, and to do it systematically, "covering" with the controlling network not only the "hot spots" of production, logistics and sales, but the whole range of parameters of the object to be managed.

The development of an industrial enterprise as a technocenosis includes a succession of successive improvements in the management system and its controlling subsystem, which already uses or in the near future will begin to use the big data technology. Then the necessary set of prerequisites for the implementation of the digital economy can be considered to be established.

The analysis of technocenosis is often likened to methods of biological research. In both cases, adaptation to environmental conditions is a decisive factor in the success of the developing entity. In the case of a controlling subsystem (and if we take a broader view - of the institution), the most important property of the environment is the dynamics of information processes. The amount of information to be processed in the controlling subsystem is continuously growing as the enterprise develops.

The answer to the intensification of the environment dynamics is the scalability of the controlling subsystem - the ability of the appropriate network (poly-process) to handle the growing amount of information. In other words, under the scalability of the controlling subsystem we understand its 
International Journal of Mathematical, Engineering and Management Sciences

Vol. 4, No. 5, 1127-1139, 2019

https://dx.doi.org/10.33889/IJMEMS.2019.4.5-089

potential to be in some sense enlarged (usually in the aspect of hardware), to adapt to the growth of volume and / or the variety of processed information.

At once we will make a reservation that discussed types of scaling have local character, i.e. they are oriented to clearly specified areas of the spectrum of input information characteristics flow. In addition, the scaling of any known type today in the course of its development faces certain limitations, which makes it necessary to seek new types of scaling.

The defining characteristics of big data are volume, velocity (speed) and variety (possibility of simultaneous processing of various types of structured and semi-structured data). We agree that these characteristics are today decisive in working with big data, but we can note that as the area develops, the list can be continued.

In Bondi (2000), the following definition is proposed: "Scalability is the ability to work with additional users or transactions by increasing resources without fundamentally restructuring the architecture or implementation model".

In the simplest case, we can say that the system, whose work after adding hardware improves in proportion to the added hardware power, is scalable (Chen et al., 2014). A more precise term is linear scalability, if we take into account the form of the graph for the dependence of system performance on the capacity of additional hardware. Linear scalability is considered a sign of an "ideal" large data processing system (Kochovski et al., 2019).

Today, in big data technologies, horizontal and vertical scaling types are used (to some extent).

With a horizontal scale-out, which means adding new hardware nodes to the computer network as needed, it is usually possible to process data distributed to hundreds and thousands of compute nodes without degrading performance (El-Rewini and Abd-El-Barr, 2005; Gluhov et al. 2018).

Vertical scaling means an upgrade (CPU, memory) of the central node of the system. In this case, there is more room for maneuvering its resources than in the case of horizontal scaling, due to the complexity of the software.

The possibilities of architectural solutions of horizontal, vertical scaling and their combinations are now being used confidently; however, the growth of the productive forces of society is largely restrained by imperfection of management systems. This defect is the main obstacle for development of the digital economy. We believe that the development of management systems will gain new opportunities in the case of mastering new forms of scaling of big data arrays.

Sources of big data are nowadays seen in the field of Internet of things, social media, internal information of enterprises, medicine, bioinformatics, astronomy (Taleb, 2007). We will focus on the subsystem of controlling of an industrial enterprise or / and the production complex, working with their internal information, both previously accumulated but not previously used, and arriving online. The problem is the efficiency of system decisions at the appeal to reality of big data in the conditions of limited resources.

\section{Methods and Proposed Solution}

We propose a new type of horizontal scaling of the big data array, consisting in its structure 
International Journal of Mathematical, Engineering and Management Sciences

Vol. 4, No. 5, 1127-1139, 2019

https://dx.doi.org/10.33889/IJMEMS.2019.4.5-089

according to the hierarchy of lifeworlds (Lebenswelt) (Husserl, 1936), which become applicable in the paradigm of a large-scale system (Klochkov et al., 2016). The so-called large-scale systems are highlighted by management science as a specific class of managed objects in the last quarter of the 20th century.

Controlling is a modern and rapidly developing independent discipline in the science of management (Poltavtseva, 2015; Utkin, 2019). At present, new broad prospects are opening up for controlling discipline. In this connection, the question arises of the possibility and necessity of extending the concept of controlling to this class of systems. The specificity of a large-scale object of control leads to an expansion of the arsenal of means both of the control itself and of its servicing subsystem of controlling.

The scientific discipline "Management of the development of large-scale systems" unfolds in Russia largely thanks to the efforts of the Institute of Control Sciences belonging to the Academy of Sciences. These efforts are officially registered since 1979 in the form of holding conferences. During this time a number of conferences, seminars and schools on this issue took place. In 2007, after a sixteen-year hiatus, the conferences on managing the development of large-scale systems were resumed on an international scale. Such conferences have become annual. However, in the proceedings of these conferences there are hardly more than one or two works, in the names of which there is the term "controlling.

If we accept the hypothesis that the annual international conferences of MLSD sufficiently reflect the state of development of methods for managing large-scale systems in the world, then we must conclude that the term "controlling of large-scale systems" is spreading slowly. This is a noteworthy paradox as the cost efficiency of ordinary enterprises that use controlling grows with their scale. We believe that controlling of large-scale systems is an actual problem of today.

Large-scale systems today mean a class of complex systems characterized by a interindustry, interregional interaction of elements distributed over a large territory, which require significant resources and time for development (Baranov and Tsvirkun, 2018).

Typical examples of large-scale systems: the fuel and energy complex and its separate branches, transport, agrarian-industrial, territorial-industrial, regional and branch systems, holdings, concerns, financial and industrial groups, distributed systems for transferring and processing information and other complexes.

According to the prevailing ideas, the main features of large-scale systems are the following:

- Significant costs of resources and time for the development of systems, the lead time for investment activities can be several years.

- Blurring of boundaries (in the process of development, the composition of the elements of the system and the nature of their interrelationships with each other and with the external environment vary significantly, the territory covered by the system can expand from regional to global scales).

- Close interconnection with other large-scale systems and with the environment.

- Complex management (in particular, coordination of sectoral, corporate and regional interests is required). 
International Journal of Mathematical, Engineering and Management Sciences

Vol. 4, No. 5, 1127-1139, 2019

https://dx.doi.org/10.33889/IJMEMS.2019.4.5-089

- Robustness and stability, small deviations in the parameters of development of individual elements and their interrelations have little effect on the development of the system as a whole.

- Other characteristics of complex (large) systems.

Note that the above definition of a large-scale system is more a working one than pretending to be of categorical severity.

The idea of a large-scale system arose from the generalization of phenomenological material of management practice of large enterprises, organizations or their associations, when it became clear that, starting from a certain scale, it became increasingly difficult to neglect some previously unobserved properties of controlled objects. It could be, for example:

- delay in logistic schemes of transportation of production, connected with the length of transport trajectories,

- the inertia of the economy of the region, the country in relation to the control signals from the center and / or the reformist aspirations of the leadership,

- manifestation of the social nature of large human communities, etc.

Not all the features of large-scale systems have an absolute character - for example, robustness and stability. So, it can hardly be categorically asserted that any large-scale system is certainly stable. More precisely, it can hardly be asserted that on the trajectory of its development there are certainly no bifurcation points in which small changes in parameters could lead to a qualitative change in the character of the motion. Of course, system architects tend to select the working areas of parameters of large-scale systems far from the mentioned bifurcation points. However, the duration of the existence of large-scale systems carries the danger of drift of the parameters of both the environment and the systems themselves in unpredictable limits. At the same time, management team does not always monitor the topology of the phase space of existence of a large-scale system and its current position in this space with sufficient accuracy for system safe navigation.

The nature of large-scale systems does not allow to neglect their social aspects. At the same time, it is proclaimed that social obligations are unconditional. However, models of large-scale systems are written in economic variables, and not in sociological ones. Social obligations are not limited to the payment of certain sums of money. Judging by their dynamics about the course of social processes can only be indirect and ambiguous (Anisimov et al., 2017; Asadpoori et al., 2018).

Modern economy in conjunction with the financial system is far from problem-free: "if the trend of replacing the real product with information services continues, the world economy will go to zero growth. The global financial system is not suitable for servicing zero growth. It is "imprisoned" for positive growth. Therefore, until the economic system is changed, it will seek on what to grow, to grasp the elements of growth, expectations will not be justified, and the economy will fail again" (Rukin et al., 2018).

Below we propose a slightly different view on the phenomenon of large-scale systems, which provides additional opportunities for structuring the ideas about the processes taking place in them. Practice shows that when the scale of an enterprise increases from a certain point, it turns out that it is necessary to take into account both economic and social processes in its functioning. Larger 
International Journal of Mathematical, Engineering and Management Sciences

Vol. 4, No. 5, 1127-1139, 2019

https://dx.doi.org/10.33889/IJMEMS.2019.4.5-089

formations - megacities, regions, countries and groups of countries, religious denominations, etc. belong to the category of subjects of history. Economic activity is conducted by them. Social actions are also important as they form historical events. Nevertheless, the basis for the subject of history is the procreational activity or reproduction of the indigenous population, which, in fact, is maintained by the economy, reflected in economic indicators, and also carries out social activities. Therefore, the subjects of the region or the country come to the need to take into account in their activities the procreative and migration processes. There is a need to classify large-scale systems in terms of the composition of processes that are essential for their modeling and management.

\section{Results}

Based on the analysis of empirical material, the following classifier is proposed. It includes four classes of systems corresponding to the following spaces: 1) economic activity (lower class); 2) social activity (middle class); 3) history space (upper class); 4) planetary space (higher class).

The criterion for classifying the system of activity and the subject implementing it to a particular class is the successive answers to a number of questions - whether the goal of the subject is to achieve and / or maintain: 1) economic solvency, 2) (in addition to the previous one) social solvency, 3) pro-creational and demographic solvency, 4) ecological solvency?

Procreation is reproduction of life, reproduction of the indigenous population. Solvency of a participant of collective activity in some aspect of this activity is ability to provide the underlying processes of the subsystem and to support the existence of the supporting structures that correspond to the considered aspect of the aggregate large-scale system for unlimited time.

Accordingly, the description tools (variables), goals and management tools of the $1^{\text {st }}$ class systems lie in the economic reality; $2^{\text {nd }}$ class - in the social reality; $3^{\text {rd }}$ class - in the procreation and demographic reality; $4^{\text {th }}$ class - in environmental activities. Each class has from one to three own main "order parameters". The variables of other classes are auxiliary (or "controlling") for the considered class. "For any system you can define few order parameters that allow you to describe its complex behavior in a fairly simple way, and also to select certain controlling parameters whose variation significantly change the macroscopic behavior of the system" (Alyushin and Knyazeva, 2008). The society as a whole is the aggregate of a certain number of subsystems of all four classes, "drawn one on another" and closely interrelated (Figure 1).

The instrumentation for the study of $3^{\text {rd }}$ class subsystems is necessary for the development and implementation of a long-term strategy of the country or group of countries, to find the balance of internal procreation-demographic donors and recipients, to develop a strategy for world development and to ensure a decent place in the world for the country. For the subject of activity of this subsystem demographic interests are always higher, than political interests and economic interests.

The instrumentation for the study of $2^{\text {nd }}$ class subsystems is necessary for the development and implementation of the strategy of concern, corporation, large enterprise for a long-term perspective, to take into account the social aspects of the life of these collective actors. 
International Journal of Mathematical, Engineering and Management Sciences

Vol. 4, No. 5, 1127-1139, 2019

https://dx.doi.org/10.33889/IJMEMS.2019.4.5-089

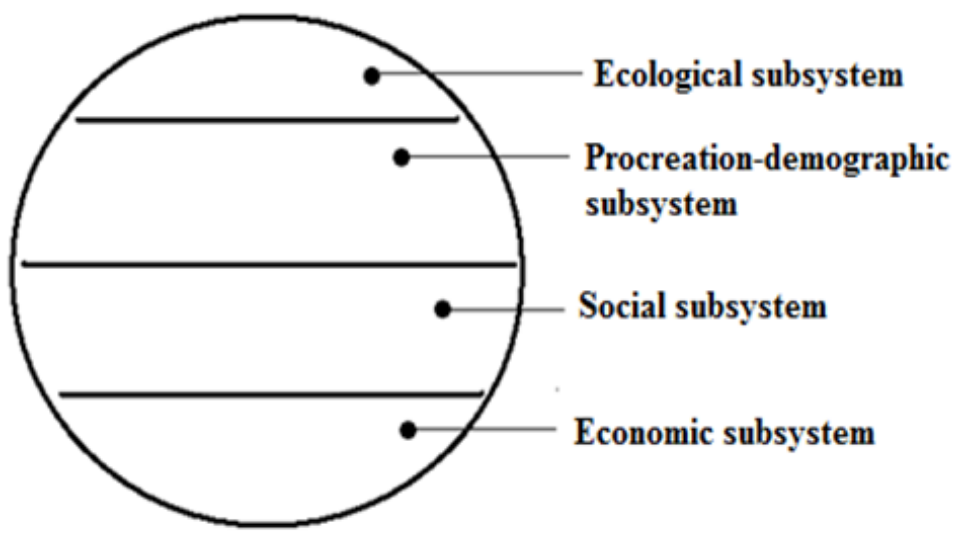

Figure 1. Representation of society as total sum of four classes of subsystems "drawn one on another"

A large-scale system is a collection of two or more "drawn one on another" subsystems belonging to different classes of the proposed classifier.

Order parameters of a system of the $2^{\text {nd }}$ class - like region, country, group of countries are procreation and migration. They become decisive in comprehending, formulating and subsequently achieving the main goal of management, which is adequate to the country-scale object. The characteristic times of change in order parameters are decisive in the development and implementation of strategies. The strategic horizon of the country's development is inappropriate to choose a shorter duration of women's passage through the fertility period (15 to 49 years). Other parameters are auxiliary from the integrity point of view that is of interest to us. It is important for economic entities of the lower classes to see their place in developing and implementing their own strategies in order to be guided by the current values of the parameters controlling their lifeworld (Lebenswelt) (Husserl, 1936; Kostin et al., 2017).

The processes of the $3^{\text {rd }}$ and $4^{\text {th }}$ levels are so slow that they were not captured by means of strategic analysis and design. Moreover, even today managers at all levels are guided primarily by economic indicators. The result of unsystematic application of economic "shockers" to Global four-level oscillatory system is the following: perturbations are growing.

At the $1^{\text {st }}$ or economic level, we can see fluctuations which are characterized by the cycles of Kitchin (2 years 4 months), Zhuglyar (10 years), Kuznets (15-20 years), Kondratyev (55 years). At the $2^{\text {nd }}$ or social level - fluctuations in social tension, revolutions, restorations, birth and death of political parties. At the $3^{\text {rd }}$ or procreation and demographic level we can fix depopulation of the developed countries of European culture (including Russia), accompanied by the demographic expansion of developing countries. At the $4^{\text {th }}$ or planetary level - irreversible warming of climate and degradation of the biosphere (Reut, 2013).

Analysis of large-scale systems is important in the context of the choice of optimal options for human interaction with these systems in the process of implementing the digital economy. 
International Journal of Mathematical, Engineering and Management Sciences

Vol. 4, No. 5, 1127-1139, 2019

https://dx.doi.org/10.33889/IJMEMS.2019.4.5-089

The phenomenon of organizing production activity is inextricably linked with the ideas of hierarchy and management. Management is an objective activity. The relationship between the operating position and the operated is displayed in the scheme of the organizational-technical system (Figure 2), proposed by philosopher G. P. Shchedrovitsky (Shchedrovitsky, 1982).

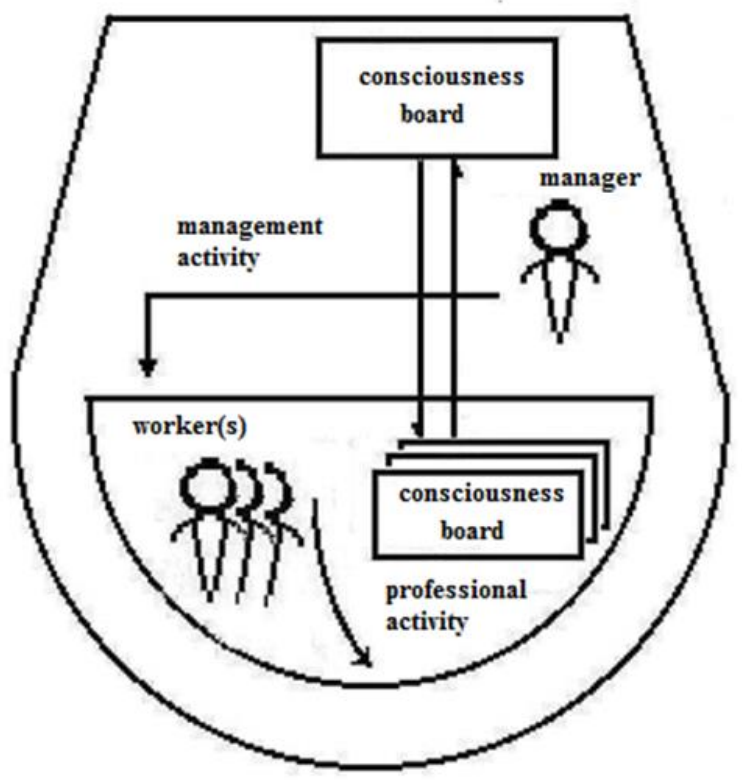

Figure 2. Classical organizational-technical system scheme (by G. P. Shchedrovitsky)

In the lower part of Figure 2, the sphere of managed activity is depicted, at the top - the sphere of management activity. The main problem introduced by the composite nature of the subject of collective activity is the coordination of the content of the manager's "consciousness board" and the controllable employees' "consciousness board".

As an example of such a hierarchical view, we point out the project activity. According to the European standard (IPMA), project activity consists, on the one hand, of the phases of project life cycle (concept, development, implementation, completion), on the other hand, of the stages of the management process (initiation, planning, organization and monitoring of implementation, analysis and regulation, closure of the project).

Growth of volumes of the processed information caused the necessity of inclusion of a new element in the scheme shown on Figure 2. This element was named "controlling service". The need for controlling (as a service function in the field of management) is explained by the phenomenon of anthropological nature, namely, the limited information-management "capacity" of an individual. The growth of manager's information burden is explained by the development of economic activity, concentration of capital, globalization, and the progress of technical means of communication. The ability of a person to implement business processes in the "two-story" scheme of the organizationaltechnical relationship "leader-subordinate" (Figure 2) is exhausted in many practical cases. 
International Journal of Mathematical, Engineering and Management Sciences

Vol. 4, No. 5, 1127-1139, 2019

https://dx.doi.org/10.33889/IJMEMS.2019.4.5-089

The trend of specialization which is congenital for the European culture, caused the decision to isolate an intermediate layer between the fields of administrative and subordinate activities and to consider it as independent service position or even institution (Figure 3) (Reut, 2013).

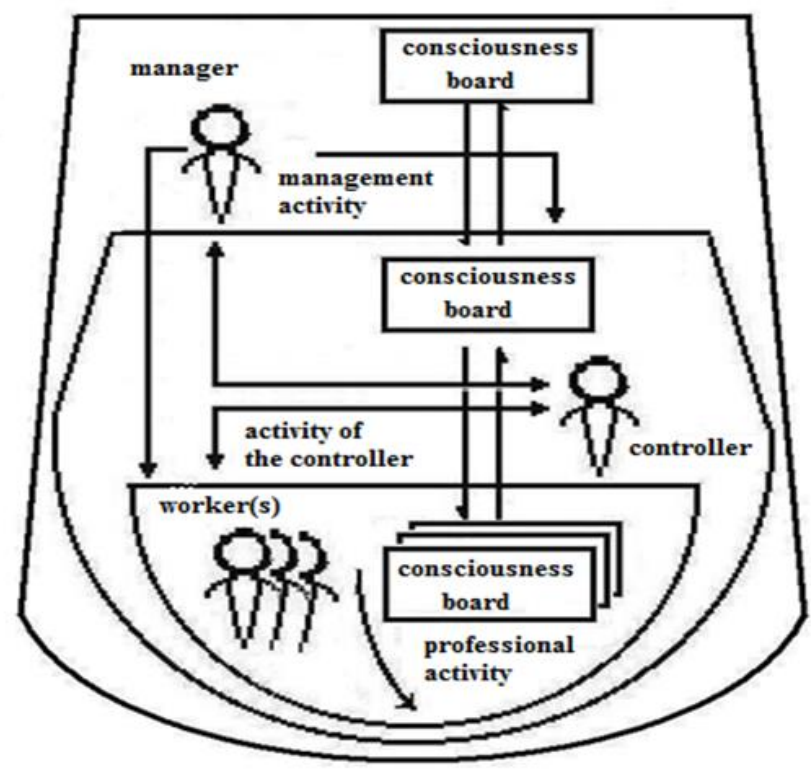

Figure 3. Stratification of collective activity structure because of its complication due to introduction of controller position

\section{Discussion}

The scheme shows that the interaction of the manager and the executors can be carried out both through the controller position and directly. The latter way of execution, as a rule, is carried out using the tools proposed by the controller institution. In practice, the function of controlling is claimed in one or another center of responsibility of the organizational structure, when the information-management "bandwidth" of the managerial unit that is responsible for this point is being exhausted.

Principles and methods of managing large-scale systems have particularities in comparison with principles and methods of management of private (small or medium) enterprises. Attempts to simply extrapolate business management techniques to sectoral, regional and state-scale systems have been insufficiently effective. Events occurring in a large-scale system and emerging problems overtake the participants' ability to recognize them.

Because of the inertia of the aggregated indicators (parameters describing the state of a large-scale system), the manager has a false impression that large-scale systems are characterized by coarseness and stability Small deviations in the parameters of development of individual elements and their interrelations have little effect on the development of the system as a whole. 
International Journal of Mathematical, Engineering and Management Sciences

Vol. 4, No. 5, 1127-1139, 2019

https://dx.doi.org/10.33889/IJMEMS.2019.4.5-089

One of the reasons of such confidence can be that owners of big systems feel like monopolists in their markets and do not realize the managerial aspects of their participation in world economy with its inevitable competition. Why will they pay for the development and implementation of new management technologies, if the existing situation is stable and seems satisfactory? It is enough to build an economically rational general control algorithm. The efforts of developers are aimed to get this result.

As adequate mechanisms for delegating authority (i.e. creating a distributed management system) are not found, it is necessary to monitor the very subtle symptoms of the development of large-scale systems. Such an analysis requires the processing of huge amounts of information, far exceeding the capabilities of an individual. Therefore, the creation of a controlling service is relevant to improvement of large-scale systems. We hope that this fact will be increasingly recognized today.

Monopoly in local markets cannot abolish global competition. This process exists objectively and manifests itself in the unevenness of world development. Russian scientist I.V. Prangishvili said that rich and poor countries do not exist, but there are countries with good and bad governance in the world.

The class of large-scale systems, on closer examination, breaks up into subclasses "drawn one on another" (Lefebvre, 1982). These subclasses are specific according to the processes taking place in them. Accordingly, they require different algorithms and management tools, including tools of the controlling institution (Reut, 2013; Gutman and Teslya, 2018).

Advent of a new stage in world development shows that even such a seemingly powerful large-scale system as the community of European countries is under threat without constructive changes in governance structures. This purpose will require new quantitative and qualitative methods.

\section{Conclusion}

(i) We believe that in the structure of a modern industrial enterprise, a number of lifeworlds can be identified. They are relatively independent of each other due to significant differences in the time scales of the processes taking place in them.

(ii) The processes of the "lower" lifeworlds may turn out to be so slow that they are not caught by means of strategic analysis of the "upper" lifeworlds. However, these processes can give a delayed cumulative effect, for example they can generate "black swans" of modern macroeconomics.

(iii) So the control system of the industrial enterprise (or industrial complex) can be divided into relatively independent subsystems. Each of subsystems corresponds to one of lifeworlds of an initial system. Each subsystem or some of them have means of processing of big data for the data corresponding to its lifeworld. Algorithms of integration of subsystems re-create logic of interrelation of lifeworlds of the industrial enterprise. In this way economy of computer performance and volumes of data storage is reached thanks to the fact that the processes belonging to different lifeworlds of an initial system are processed with different discretization. 
International Journal of Mathematical, Engineering and Management Sciences

Vol. 4, No. 5, 1127-1139, 2019

https://dx.doi.org/10.33889/IJMEMS.2019.4.5-089

(iv) This idea can be applied to larger objects (region, country, World). In this case the control loop of a system in general includes only the order parameters relating to the top level of a system. It can be a region, a country, global digital economy (Orlov, 1976; Reut, 2018), Functionalist-Organic Information Economy (Orlov, 2013), etc. Influences of other variables are considered by introduction of cross-connections between subsystems.

\section{Conflict of Interest}

The authors confirm that there is no conflict of interest to declare for this publication.

\section{Acknowledgement}

The research carried out with the support of Bauman Moscow State Technical University (BMSTU).

\section{References}

Akyildiz, I.F., Su, W., Sankarasubramaniam, Y., \& Cayirci, E. (2002). Wireless sensor networks: a survey. Computer Networks, 38(4), 393-422.

Alyushin, A.L., \& Knyazev, E.N. (2008). Lebenswelt: Speed of perception and time scales. LKI publishing house. [In Russian].

Anisimov, V.G., Anisimov, E.G., Saurenko, T.N., \& Sonkin, M.A. (2017, January). The model and the planning method of volume and variety assessment of innovative products in an industrial enterprise. In Journal of Physics: Conference Series, 803(1), IOP Publishing.

Asadpoori, A., Ankomah, C., Asadpoori, A., Derevianko, O., \& Shaburov, E. (2018). Sustained municipal waste management models in Russian megapolicies through utilizing waste-to-energy technologies. In MATEC Web of Conferences, (Vol. 193, p. 02039). EDP Sciences.

Baranov, V.V., \& Tsvirkun, A.D. (2018). Development control: structural analysis, problems, stability. Automation and Remote Control, 79(10), 1780-1796.

Bondi, A.B. (2000, September). Characteristics of scalability and their impact on performance. In Proceedings of the 2nd International Workshop on Software and Performance, (pp. 195-203). ACM.

Chen, M., Mao, S., Zhang, Y., \& Leung, V.C.M. (2014). Big data. related technologies, challenges and future prospects. Springer, Cham. ISBN: 978-3-319-06244-0.

Cukier, K. (March 5, 2013). Big data: a revolution that will transform how we live, work, and think (1st ed.). Boston: Houghton Mifflin Harcourt. p. 256.

Denning, P.J., \& Lewis, T.G. (2017). Exponential laws of computing growth, Communications of the ACM, 60(1), pp. 54-65.

El-Rewini, H., \& Abd-El-Barr, M. (2005). Advanced computer architecture and parallel processing, (Vol. 42). John Wiley \& Sons.

Gluhov, V., Leventsov, V., Radaev, A., \& Nikolaevskiy, N. (2018). Analytical modeling of development and implementation of telecommunication technologies. In Internet of Things, Smart Spaces, and Next Generation Networks and Systems, (pp. 428-440). Springer, Cham.

Gorodetskiy, A.E., Kurbanov, V.G., \& Tarasova, I.L. (2018). Decision-making in central nervous system of a robot (pp. 21-30). Informatsionno-Upravliaiushchie Sistemy. [In Russian]. 
International Journal of Mathematical, Engineering and Management Sciences

Vol. 4, No. 5, 1127-1139, 2019

https://dx.doi.org/10.33889/IJMEMS.2019.4.5-089

Grishchenko, O.V., Kireev, V.S., Dubrova, L.I., Yanenko, M.B., \& Vakulenko, R.Ya. (2016). Organization, planning and control of marketing logistics. International Journal of Economics and Financial Issues, 6(8 Special Issue), pp. 166-172.

Gutman, S., \& Teslya, A. (2018, August). Environmental safety as an element of single-industry towns' sustainable development in the Arctic region. In IOP Conference Series: Earth and Environmental Science, 180(1), pp. 012010. IOP Publishing.

Husserl E. (1936). The crisis of the European sciences and transcendental phenomenology: An Introduction to Phenomenological Philosophy, (Vol. 405). Brill-Nijhoff.

Klochkov, Y., Klochkova, E., Antipova, O., Kiyatkina, E., Vasilieva, I., \& Knyazkina, E. (2016, September). Model of database design in the conditions of limited resources. In 2016 th International Conference on Reliability, Infocom Technologies and Optimization (Trends and Future Directions)(ICRITO), (pp. 64-66). IEEE.

Knight, W. (2017). Ibm raises the bar with a 50-qubit quantum computer. Sighted at MIT Review Technology.

Kochovski, P., Drobintsev, P.D., \& Stankovski, V. (2019). Formal quality of service assurances, ranking and verification of cloud deployment options with a probabilistic model checking method. Information and Software Technology, 109, 14-25.

Kostin, G.A., Pokrovskaia, N.N., \& Ababkova, M.U. (2017, October). Master-chain as an intellectual governing system for producing and transfer of knowledge. In 2017 IEEE II International Conference on Control in Technical Systems (CTS), (pp. 71-74). IEEE.

Kozlov, A.V., Rytova, E.V., Gutman, S.S., \& Zaychenko, I.M. (2016). The valuing of the indicator of a regional industrial development: The fuzzy logic approach. Paper presented at the Proceedings of the 19th International Conference on Soft Computing and Measurements, SCM 2016, 545-547. IEEE.

Lefebvre V.A. (1982). Algebra of conscience. Dordrecht: Reidel, pp. 222.

Levis, P., Madden, S., \& Pollasre, J. (2005). TinyOS: an operating system for wireless sensor networks, In Ambient Intelligence, W. Weber, J.M. Rabaey, E. Aarts (Eds.). New York, NY: Springer-Verlag.

Mayer-Schönberger, V., \& Cukier, K. (2013). Big data: a revolution that will transform how we live, work, and think. Houghton Mifflin Harcourt.

Metz, R (2018). Social networks are broken. This man wants to fix them, MIT Technology Review.

Orlov, A.I. (1976, 24-27 Augus,). Stability in Discrete Economic and Inventory Models. In Econometric Society European Meeting, Helsinki.

Orlov, A.I. (2013). Functionalist-organic information economy-the organizational-economic theory of innovation development. Biocosmology-neo-Aristotelism. Bilingual Electronic Journal of Universalizing Scientific and Philosophical Research based upon the Original Aristotelian Cosmological Organicism, 3(1), 52-59.

Poltavtseva, M.A. (2015). Support of the integrity of administrative information in intensive data exchange with RDBMS clients. Automatic Control and Computer Sciences, 49(8), 690-695.

Reut, D.V. (2013). Large-scale systems: management, methodology, controlling. MSTU publishing house of N.E. Bauman. [In Russian], pp. 184.

Reut, D.V. (2018, September). Semiotics machine named "Kaleidoscopical Configurator": a model of digital economy existence mode and an instrument of digital Economy Improvement. OR60: The OR Society Annual Conference. Lancaster University. Conference Handbook, pp. 199-200.

Romanenko, Y.M., Shipunova, O.D., Mureyko, L.V., Serkova, V.A., \& Romanenko, I.B. (2016). The time factor in consciousness construction. Indian Journal of Science and Technology, 9(42), 1-10. 
International Journal of Mathematical, Engineering and Management Sciences

Vol. 4, No. 5, 1127-1139, 2019

https://dx.doi.org/10.33889/IJMEMS.2019.4.5-089

Rukin, E., Moroz, A., Smirnov, K., Davydov, V., \& Yushkova, V. (2018). The development of a new method for making justified decisions by municipal authorities in the management of territories on the basis of the results of the environmental express-control of the state of various media. In MATEC Web of Conferences, (Vol. 245, p. 12002). EDP Sciences.

Shchedrovitsky, G.P. (1982). Methodological organization of systems-structural research and development: principles and general scheme. General 27. https://www.fondgp.ru/publications/methodological-organization-of-systems-structural-research-anddevelopment-principles-and-general-framework/

Taleb, N.N. (2007). The black swan: the impact of the highly improbable. Random House (US), pp. 400.

Tishina, E.A., Rezantseva, E.Y., \& Reut, D.V. (2017, October). The concept of digital transformation of the society. In 2017 Tenth International Conference Management of Large-Scale System Development (MLSD), (pp. 1-5). IEEE.

Utkin, L.V. (2019). An imprecise extension of SVM-based machine learning models. Neurocomputing, 331, 18-32. 